\title{
Evaluation of Duodenal Hypersensitivity to Acid Using Transnasal Endoscopy
}

\author{
Manabu Ishii et al.* \\ Division of Gastroenterology department of Internal Medicine, \\ Kawasaki Medical School, Kurashiki, \\ Japan
}

\section{Introduction}

According to the Rome III classification, functional gastroduodenal disorders (FGIDs) in adults are subdivided into six domains. Functional dyspepsia (FD) is a subcategory of the FGIDs. It is characterized by the presence of symptoms that are believed to be associated with gastroduodenal lesions, particularly epigastric pain or burning, postprandial fullness, or early satiation, without the evidence of organic disease to explain the onset of these symptoms at least 6 months before diagnosis (Tach J et al., 2006). Furthermore, FD is divided into 2 subtypes postprandial distress syndrome (PDS) and epigastric pain syndrome (EPS). The diagnostic criteria for PDS include the presence of 1 or both of the following symptoms several times in a week: bothersome postprandial fullness occurring after ordinary-sized meals, and early satiation that prevents finishing a regular meal. The diagnostic criteria for EPS include the presence of all of the following symptoms: moderately severe pain or burning localized to the epigastrium at least once per week, and intermittent pain, not generalized or localized to other abdominal or chest regions, not relieved by defecation or passage of flatus, and not fulfilling the criteria for gallbladder and sphincter of Oddi disorders.

FD is a functional disorder that affects $10-30 \%$ of the population worldwide. The results of an Itarian population-based study, indicated that the prevalence rates of FD were $11 \%$. Of these, PDS, EPS, and PDS accompanied with EPS were $67.5 \%, 48.2 \%$, and $15.8 \%$ respectively (Zagari RM et al.,2010). The results of a Swedish population-based study, indicated that the prevalence rates of FD, PDS, EPS, and PDS accompanied with EPS were 15.7\%, 12.2\%, 5.5\%, and $1.7 \%$, respectively (Aro P et al., 2009). The results of a Norwegian population-based study, showed that the lifetime prevalence rate of FD was $23 \%$ in men and $18 \%$ in women (Johnsen et al., 1988), and that in the United States, was 29\% (Shaib Y et al., 2004).

\footnotetext{
${ }^{*}$ Hiroaki Kusunoki², Noriaki Manabe ${ }^{3}$, Tomoari Kamada1, Ken-ichi Tarumi ${ }^{1}$, Hiroshi Matsumoto1, Motonori Sato ${ }^{1}$, Yoshiyuki Yamanaka ${ }^{1}$, Takahisa Murao ${ }^{1}$, Hideaki Tsutsui ${ }^{1}$, Akiko Shiotani ${ }^{1}$, Jiro Hata ${ }^{3}$, and Ken Haruma ${ }^{1}$

${ }^{1}$ Division of Gastroenterology department of Internal Medicine, ${ }^{2}$ Division of General Medicine ${ }^{3}$ Division of Endoscopy and Ultrasound Department of Clinical Pathology and Laboratory Medicine, Kawasaki Medical School, Kurashiki, Japan
} 


\section{Pathogenesis and evaluation}

Different factors such as delayed gastric emptying (Stanghellini V et al., 1996; Sarnelli G et al., 2003), hypersensitivity to gastric distension (Bradette M et al., 1991; Mearin F et al., 1991; Barbera R et al., 1995; Tack J et al., 2001), impaired gastric accommodation to a meal (Tach J et al., 1998), abnormal duodenojejunal motility (Holtmann G et al., 1996; Wilmer A et al., 1998), duodenal motor and sensory dysfunction (Samsom M et al., 1999; Schwarz MP et al., 2001), duodenal hypersensitivity (Schwartz MP et al., 2001), Helicobacter pylori infection, and psychosocial factors have been implicated in the pathogenesis of FD. Among these factors, acid is thought to be more important because proton pump inhibitors (PPIs) and histamine 2 (H2)-receptor antagonists have been proposed to be effective therapies for a subset of patients with FD.

\subsection{Duodenal hypersensitivity to acid in patients with FD}

Lee et al. (2004) reported that acid infusion into the duodenal bulb induced dyspepsia in healthy volunteers, and the symptoms of dyspepsia are more readily observed in patients with FD than in healthy subjects (Samsom et al., 1999). Increased duodenal acid exposure plays a role in the onset of dyspeptic symptoms in patients with FD having prominent nausea (Lee et al., 2004). A recent study indicated that acid infusion into the stomach predominantly induced dysmotility-like dyspeptic symptoms in healthy Japanese control subjects (Miwa et al., 2007). PPIs and H2-receptor antagonists have been proposed as effective therapies for treating FD (Delaney et al., 2005; Veldhuyzen van Zanten et al., 2005; Kinoshita et al., 2005; Seno et al. 2005). Guidelines for the management of dyspepsia suggest that PPI therapy is more effective than a placebo or H2-receptor antagonists in relieving the symptoms of patients with uninvestigated dyspepsia (Talley et al., 2005).

\subsection{Duodenal acid and gastroduodenal motility}

Duodenal acidification suppresses antral contractions. Matsunaga et al. (1994) reported that intragastric acidification and intraduodenal acidification at $\mathrm{pH} 1.0$ inhibited spontaneous phase III activity in dogs. Simrén et al. (2003) reported that after acid infusion in healthy volunteers, antral contractions were lesser and the number of contractions in the proximal duodenum was greater than those before the infusion. It has been shown that the greater the concentration of acid in the duodenum, the greater is the inhibition of gastric emptying (Hunt et al., 1972). Duodenal $\mathrm{pH}$ influences interdigestive gastric motility in humans. Lowering of the duodenal $\mathrm{pH}$ prevents the occurrence of the gastric phase III (Woodtli et al., 1995), and, in animals, duodenal acidification induces gastric relaxation by exerting an inhibitory effect on the stomach (Lu et al., 1999). Duodenal acidification has an inhibitory effect on gastric emptying (Danzer et al., 2004; Raybould et al., 1993; Cooke, 1974; Mearadji et al., 1999; Parkman et al., 1998), and hydrochloric acid ( $\mathrm{HCl})$ may restrict gastric outflow by inducing tonic occlusion of the duodenum (Parkman et al., 1998).

\subsection{Pathophysiological mechanism of acid-sensing system}

Visceral organs receive dual innervation from primary afferents commonly referred to as sympathetic afferents (splanchnic nerves) and parasympathetic afferents (vagus nerves). Lamb et al. (2003) reported that electromyographically recorded visceromotor responses increased after $\mathrm{HCl}$ administration in rats, but vagotomy and pretreatment with capsaicin abolished these responses. Their findings indicated that vagal pathways are involved in 
mediating signals for the noxious stimulation of the stomach. Further, Scicho et al. (2005) reported that gastric acidification increased the expression of phosphorylated extracellular signal-regulated kinase-1 and -2 (p-ERK1/2) in the dorsal root ganglion neurons via $N$ methyl-D-aspartate receptors. They suggested that sympathetic pathways are involved in mediating signals for noxious stimulation of the stomach. Noxious mechanical stimulation showed that most of the increased p-ERK1/2 neurons coexpressed transient receptor potential vanilloid receptor 1 and acid-sensing ion channel 3 (Sakurai et al., 2008).

Transient receptor potential vanilloid receptor 1 and the acid-sensing ion channel 3 are largely involved in the acid-induced nociception in mammals (Ugawa et al., 2002), but it is still unknown which receptors of the peripheral sensory pathways encode and integrate an acidinduced nociceptive event in the gastric mucosa and the duodenal mucosa. Akiba et al. (2002) reported that the capsaicin pathway is an acid-sensing pathway that promotes hyperemia and mucus secretion in response to luminal acid in the duodenum.

\subsection{Method for evaluating duodenal hypersensitivity to acid and gastric motility}

Duodenal hypersensitivity to acid is one of the more important factors in the pathogenesis of FD. Although manometric methods, scintigraphic methods, electrogastrography and ultrasonography have been used to evaluate enterokinesis, a practical method for evaluating duodenal hypersensitivity to acid has not been reported. Transnasal endoscopy is a rescently developed, non-invasive and nondiscomforting method for examination of the upper gastrointestinal tract (Yagi et al., 2005; Murata et al., 2007). We developed a new method for evaluating duodenal hypersensitivity to acid and gastric motility by duodenal acidification using transnasal endoscopy (Ishii et al., 2008).

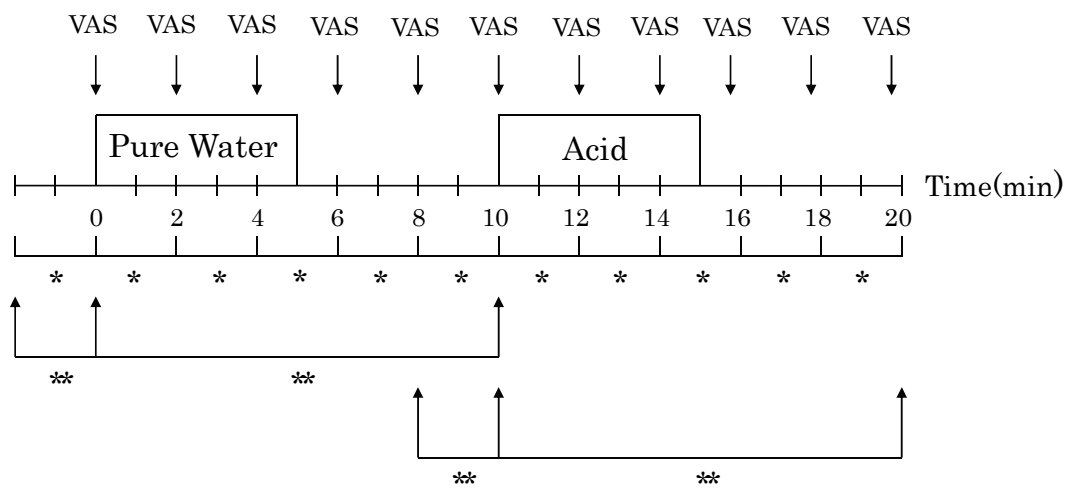

Fig. 1. *Number of antral contractions every two minutes; **Motility number; VAS: Visual Analogue Scale

The study protocol is shown in Fig. 1. All subjects underwent transnasal endoscopy as required in the left lateral decubitus position in the morning after overnight fasting. The infusion of air into their stomachs was minimized in order to observe their gastric motility. An infusion tube (outer diameter $1.5 \mathrm{~mm}$ ) was then introduced by transnasal endoscopy until the tip was located in the duodenal bulb. The subjects changed their body position to the supine position, and their antral contractions and dyspeptic symptoms were evaluated before and after a duodenal infusion of pure water $\left(36.5^{\circ} \mathrm{C}, 100 \mathrm{ml}\right)$ and acid $\left(36.5^{\circ} \mathrm{C}, 0.1 \mathrm{~N}\right.$ 
$\mathrm{HCl}, 100 \mathrm{ml}$ ). The images of transnasal endoscopy were recorded from the beginning until the end on a DVD and were analyzed after finishing the examination. We infused $100 \mathrm{ml}$ of pure water and acid at a rate of $20 \mathrm{ml} / \mathrm{min}$. The use of an electronic infusion pump, ensured

\begin{tabular}{|c|c|c|c|}
\hline & $2 \mathrm{~min}$ & $4 \mathrm{~min}$ & $6 \mathrm{~min}$ \\
\hline Heavy feeling in the stomach & 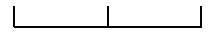 & 1 & \llcorner \\
\hline Nausea or feeling sick & $\perp$ & 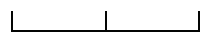 & \llcorner \\
\hline Bloating & ل & ل & \llcorner \\
\hline Belching & ل & $\perp$ & L \\
\hline Cramping pain in the stomach & 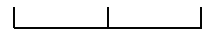 & $\perp$ & \llcorner \\
\hline Dull pain in the stomach & ل & $\perp$ & L \\
\hline Pricking pain in the stomach & ل & ل & L \\
\hline Tickling or tingling in the throat & 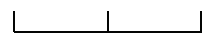 & ل & $L$ \\
\hline Sour or bitter taste & ل & ل & L \\
\hline Feeling that something is stuck in the throat & \llcorner & ل & L \\
\hline Burning sensation in the chest & 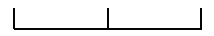 & $\perp$ & $L$ \\
\hline
\end{tabular}

Fig. 2.

\begin{tabular}{|c|c|c|c|}
\hline \multirow{2}{*}{ Symptoms } & \multicolumn{3}{|c|}{$\begin{array}{c}\text { Maximum severity scale }(\mathrm{cm}) \\
(\text { Mean } \pm \text { SEM })\end{array}$} \\
\hline & $0.1 \mathrm{~mol} / \mathrm{L} \mathrm{HCl}$ & Pure Water & P-value \\
\hline Heavy feeling in the stomach & $4.76 \pm 0.74$ & $0.54 \pm 0.24$ & 0.0001 \\
\hline Nausea or feeling sick & $4.65 \pm 1.1$ & $0.19 \pm 0.16$ & 0.001 \\
\hline Bloating & $3.66 \pm 0.8$ & $0.54 \pm 0.24$ & 0.0006 \\
\hline Belching & $1.61 \pm 0.61$ & $0.76 \pm 1.1$ & 0.2349 \\
\hline Cramping pain in the stomach & $3.39 \pm 0.88$ & $1.0 \pm 0.45$ & 0.0016 \\
\hline Dull pain in the stomach & $4.05 \pm 0.83$ & $0.49 \pm 0.23$ & 0.0005 \\
\hline Pricking pain in the stomach & $1.58 \pm 0.72$ & $0.51 \pm 0.75$ & 0.125 \\
\hline Tickling or tingling in the throat & $2.35 \pm 0.91$ & $0.42 \pm 0.17$ & 0.0539 \\
\hline Sour or bitter taste & $1.1 \pm 0.16$ & $0.55 \pm 0.09$ & 0.0982 \\
\hline $\begin{array}{r}\text { Feeling that something is stuck } \\
\text { in the throat }\end{array}$ & $1.6 \pm 0.64$ & $0.45 \pm 0.25$ & 0.0932 \\
\hline Burning sensation in the chest & $2.67 \pm 0.75$ & $0.16 \pm 0.1$ & 0.0033 \\
\hline
\end{tabular}

Maximum severity on the $10 \mathrm{~cm}$ visual analogue scale after infusion of $0.1 \mathrm{~mol} / \mathrm{L}$ hydrochloric acid $(\mathrm{HCl})$ or pure water $(\mathrm{n}=14)$

Table 1. 
that the subjects were blinded to the nature (acid or pure water) of the infusion. The acid infusion was started $5 \mathrm{~min}$ after the infusion of pure water was finished. The severity of each symptom was assessed by each subject using a $10-\mathrm{cm}$ visual analogue scale every $2 \mathrm{~min}$ (Fig. 2). The symptoms assessed were as follows: a heavy feeling in the stomach, bloating, nausea or feeling sick, belching, a dull pain in the stomach, cramping pain in the stomach, a pricking pain in the stomach, tickling or tingling sensation in the throat, a sour or bitter taste, a feeling that something is stuck in the throat, and a burning sensation in the chest. The symptom severity scales were set at $0 \mathrm{~cm}$ before the duodenal infusion of water and acid. The maximum severity scale was calculated as the mean of the individual maximum values. We evaluated the differences between the maximum severity scales in the infusion of pure water and acid. Antral contractions beginning every 2 min before the duodenal infusion of water were counted every $2 \mathrm{~min}$ until the end of the examination. The macroscopic waves of gastric peristalsis propagating from the gastric body to the antrum were counted. The motility number was defined as the mean number of antral contractions in $1 \mathrm{~min}$. We evaluated the differences between the motility numbers before and after the infusion of pure water and those before and after acid infusion. We compared the changes in the symptom severity scales, the maximum severity scales of each subject, the number of antral contractions, and the motility number between the acid and pure water infusion. Using this method, we showed that the maximum severity scale of a heavy feeling in the stomach, and other symptoms was significantly greater after the acid infusion than the pure water infusion in healthy volunteers (Table 1). During pure water infusion, no changes were observed between the motility numbers. On the other hand, the motility number significantly decreased after duodenal acidification (before $v s$. after: $2.93 \pm 0.12$ times vs. 1.11 \pm 0.23 times, $P<0.0001$ ) (Fig. 3).
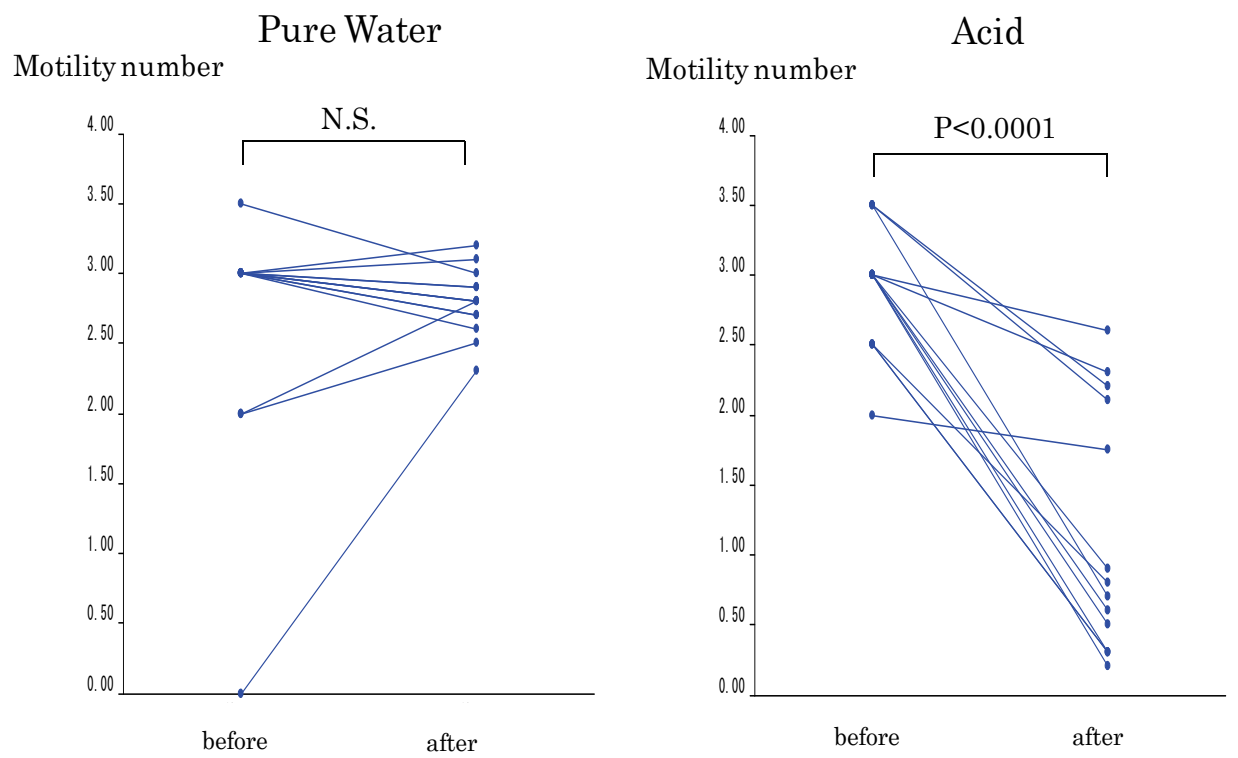

Fig. 3. 
Furthermore, using this method we evaluated duodenal hypersensitivity to acid in healthy volunteers and patients with FD (Ishii et al., 2010). The study protocol is shown in Fig. 4. In this study, we infused the patients with $20 \mathrm{ml}$ of $\mathrm{HCl}$ at a rate of $20 \mathrm{ml} / \mathrm{min}$. The severity of 12 symptoms was assessed by each subject using a $100-\mathrm{mm}$ visual analogue scale (VAS) from the time acid infusion was started up to $30 \mathrm{~min}$ after the initiation of the infusion.

\section{Protocol}

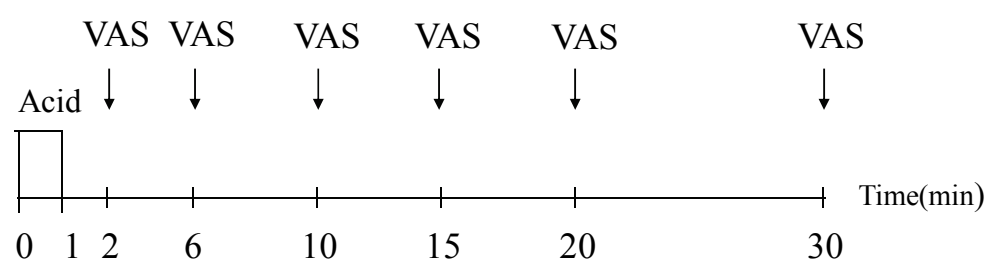

Fig. 4. Study protocols. This study consisted of monitoring of the assessment of symptoms using VAS

\begin{tabular}{lccc}
\hline \hline & \multicolumn{3}{c}{$\begin{array}{c}\text { Maximum severity scale }(\mathrm{mm}) \\
\text { (Mean } \pm \text { SEM) }\end{array}$} \\
\cline { 2 - 4 } Symptoms & $\begin{array}{c}\text { Patients with } \\
\text { FD }\end{array}$ & $\begin{array}{l}\text { Healthy } \\
\text { volunteers }\end{array}$ & P-value \\
\hline Heavy feeling in the stomach & $25.5 \pm 4.4$ & $5.9 \pm 2.0$ & $<0.001^{*}$ \\
Nausea or feeling sick & $14.4 \pm 4.3$ & $4.4 \pm 1.9$ & $0.036^{*}$ \\
Bloating & $39.1 \pm 5.1$ & $14 \pm 3.5$ & $<0.001^{*}$ \\
Belching & $20.0 \pm 4.9$ & $9.6 \pm 6.3$ & 0.254 \\
Cramping pain in the stomach & $19.4 \pm 5.0$ & $5.4 \pm 2.7$ & $0.017^{*}$ \\
Dull pain in the stomach & $21.8 \pm 5.0$ & $4.5 \pm 2.3$ & $0.003^{*}$ \\
Prickling pain in the stomach & $12.9 \pm 4.1$ & $4.8 \pm 2.2$ & 0.084 \\
Tickling or tingling in the throat & $9.7 \pm 3.2$ & $0.6 \pm 0.6$ & $0.008^{*}$ \\
Sour or bitter taste & $8.9 \pm 3.1$ & $0.6 \pm 0.6$ & $0.011^{*}$ \\
Feeling that something is stuck & $18.6 \pm 4.3$ & $1.9 \pm 1.1$ & $<0.001^{*}$ \\
Burning sensation in the chest & $10.6 \pm 3.6$ & $3.1 \pm 2.0$ & 0.073 \\
Early satiety & $35.6 \pm 5.3$ & $9.0 \pm 3.9$ & $<0.001^{*}$ \\
\hline
\end{tabular}

Maximum severity on the 100-mm visual analogue scale after infusion of $0.1 \mathrm{~mol} / \mathrm{L}$ hydrochloric acid $(\mathrm{HCl})$ between healthy volunteers and patients with FD.

${ }^{*} \mathrm{P}<0.05,2$-sided non-paired $t$ test

Table 2. Maximum severity scales between healthy volunteers and patients with FD

The maximum severity scale was defined as the maximum score of the symptom severity scale. The VAS was set at $0 \mathrm{~mm}$ just before the duodenal infusion of acid. The total score was defined as the aggregate score of the maximum severity scale for the 12 symptoms. 
The differences in the rate of incidence of dyspeptic symptoms, maximum severity scales, and total scores between patients with FD and healthy volunteers were evaluated.

The rates of dyspeptic symptoms in patients with FD and healthy volunteers after acid infusion were $88.6 \%$ and $75 \%$, respectively $\left(P=\right.$ not significant, using the $\mathrm{X}^{2}$-test). The maximum severity scales of a heavy feeling in the stomach, nausea or feeling sick, bloating, cramping pain in the stomach, dull pain in the stomach, tickling or tingling in the throat, sour or bitter taste, feeling that something is stuck in the throat and early satiety significantly increased after acid infusion in patients with FD than in healthy volunteers $(P<$ 0.05 , using the two-sided non-paired $t$-test) (Table 2). There were significant differences in the total scores (patients with FD vs healthy volunteers: $233.8 \pm 37.8$ vs $63.9 \pm 14.6$; $P<0.001$, using the two-sided nonpaired $t$-test) (Fig. 5). We found that duodenal acidification induced dyspeptic symptoms more significantly in patients with FD than in healthy volunteers.

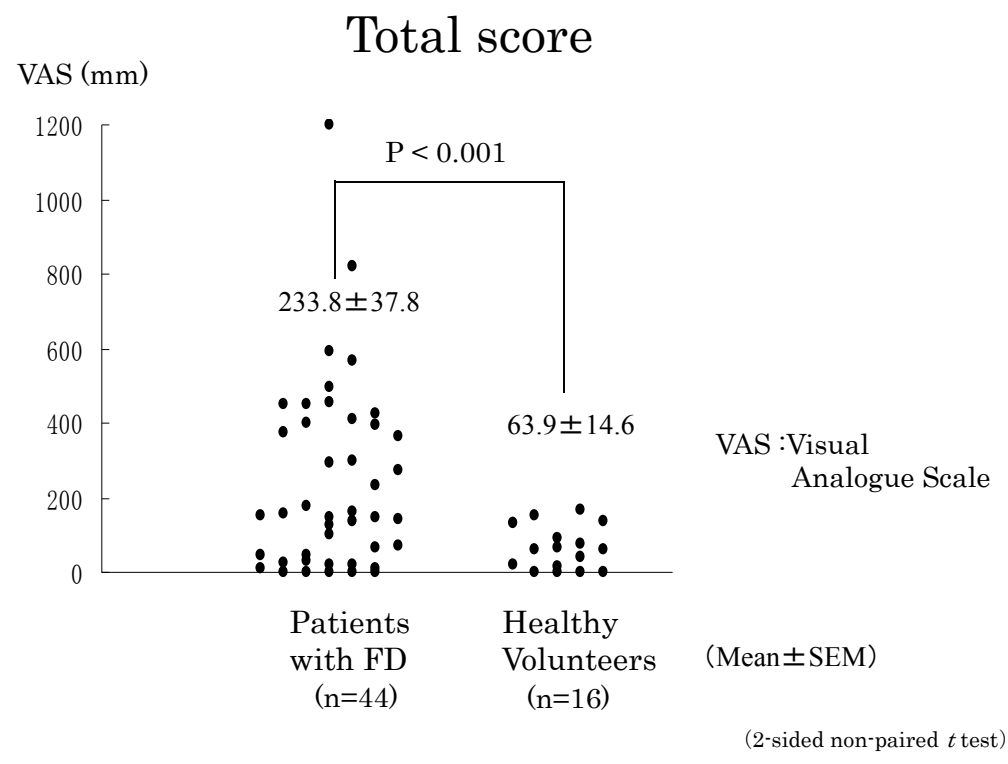

Fig. 5.

\section{Conclusion}

The effects of duodenal acidification by transnasal endoscopy significantly increased various dyspeptic symptoms not suppresses this symptoms. Further, this method enabled the evaluation of duodenal hypersensitivity to acid in healthy volunteers and in patients with FD. Using this method, we might be able to clarify a correlation between duodenal hypersensitivity to acid and the effectiveness of PPI therapy for the treatment of FD. A further examination is needed.

\section{Acknowledgment}

We thank nurses and officers at the Kawasaki Medical School for their kind help with the present survey. 


\section{References}

[1] Tack, J.; Talley, N.J. \& Camilleri, M. (2006). Functional gastroduodenal disorders. Gastroenterol. 130: 1466-1479.

[2] Zagari RM,; Law GR \& Fuccio L. (2010). Epidemiology of functional dyspepsia and subgroups in the Italian general population: an endoscopic study. Gastroenterol. 138:1302-11.

[3] Aro, P.; Talley, N.J. \& Ronkainen, J. (2009). Anxiety is associated with uninvestigated and functional dyspepsia (Rome III criteria) in a Swedish population-based study. Gastroenterol. 137: 94-100.

[4] Johnsen, R.; Straume, B. \& Førde, O.H. (1988). Peptic ulcer and non-ulcer dyspepsia-a disease and a disorder. Scand. J. Prim. Health Care 6: 239-243.

[5] Shaib, Y.; \& El-Serag, H.B. (2004). The prevalence and risk factors of functional dyspepsia in a multiethnic population in the United States. Am. J. Gastroenterol. 99: 2210-2216.

[6] Stanghellini, V.; Tosetti, C. \& Pasternico, A. (1996). Risk indicators of delayed gastric emptying of solids in patients with functional dyspepsia. Gastroenterol. 110: 10361042.

[7] Sarnelli, G.; Caenepeel, P. \& Geypens, B. (2003). Symptoms associated with impaired gastric emptying of solids and liquids in functional dyspepsia. Am. J. Gastroenterol. 98: 783-788.

[8] Bradette, M.; Pare, P. \& Douville, P. (1991). Visceral perception in health and functional dyspepsia. Crossover study of gastric distension with placebo and domperidone. Dig. Dis. Sci. 36: 52-58.

[9] Mearin, F.; Cucala, M. \& Azpiroz, F. (1991). The origin of symptoms on the brain-gut axis in functional dyspepsia. Gastroenterol. 101: 999-1006.

[10] Barbera, R.; Feinle, C. \& Read, N.W. (1995). Nutrient-specific modulation of gastric mechanosensitivity in patients with functional dyspepsia. Dig. Dis. Sci. 40: 16361641.

[11] Tack, J.; Caenepeel, P. \& Fischler, B. (2001). Symptoms associated with hypersensitivity to gastric distension in functional dyspepsia. Gastroenterol. 121: 526-535.

[12] Tack, J.; Piessevaux, H. \& Coulie, B. (1998). Role of impaired gastric accommodation to a meal in functional dyspepsia. Gastroenterol. 115: 1346-1352.

[13] Holtmann, G.; Goebell, H. \& Talley, J. (1996). Impaired small intestinal peristaltic reflexes and sensory thresholds are independent functional disturbances in patients with chronic unexplained dyspepsia. Am. J. Gastroenterol. 91: 485-491.

[14] Wilmer, A.; Van Cutsem, E. \& Andrioli, A. (1998). Ambulatory gastrojejunal manometry in severe motility-like dyspepsia: lack of correlation between dysmotility, symptoms, and gastric emptying. Gut 42: 235-242.

[15] Samsom, M.; Verhagen, M.A. \& van Berge Henegouwen, G.P. (1999). Abnormal clearance of exogenous acid and increased acid sensitivity of proximal duodenum in dyspeptic patients. Gastroenterol. 116: 515-520.

[16] Schwartz, M.P.; Samsom, M. \& van Berge Henegouwen, G.P. (2001). Effect of inhibition of gastric acid secretion on antropyloroduodenal motor activity and duodenal acid hypersensitivity in functional dyspepsia. Aliment. Pharmacol. Ther. 15: 1921-1928.

[17] Schwarz, M.P.; Samsom, M. \& Smout, A.J. (2001). Chemospecific alterations in duodenal perception and motor response in functional dyspepsia. Am. J. Gastroenterol. 96: 2596-2602. 
[18] Lee, K.J.; Demarchi, B. \& Demedts, I. (2004). A pilot study on duodenal acid exposure and its relationship to symptoms in functional dyspepsia with prominent nausea. Am. J. Gastroenterol. 99: 1765-1773.

[19] Samsom, M.; Verhagen, M.A. \& van Berge Henegouwen, G.P. (1999). Abnormal clearance of exogenous acid and increased acid sensitivity of proximal duodenum in dyspeptic patients. Gastroenterol. 116: 515-520.

[20] Lee, K.J.; Vos, R. \& Janssens, J. (2004). Influence of duodenal acidification on the sensorimotor function of the proximal stomach in humans. Am. J. Physiol. 286: G278- G284.

[21] Miwa, H.; Nakajima, K. \& Yamaguchi, K. (2007). Generation of dyspeptic symptoms by direct acid infusion into the stomach of healthy Japanese subjects. Aliment. Pharmacol. Ther. 26: 257- 264.

[22] Delaney, B.; Ford, A.C. \& Forman, D. (2005). Initial management strategies for dyspepsia. Cochrane Database Syst. Rev. 4: CD001961.

[23] Veldhuyzen,; van Zanten S.J. \& Chiba, N. (2005). A randomized trial comparing omeprazole, ranitidine, cisapride, or placebo in helicobacter pylori negative, primary care patients with dyspepsia: the CADET-HN Study. Am. J. Gastroenterol. 100: 1477-1488.

[24] Kinoshita, Y.; Hashimoto, T. \& Kawamura, A. (2005). Effects of famotidine, mosapride and tandospirone for treatment of functional dyspepsia. Aliment. Pharmacol. Ther. 21 (Suppl. 2): 37-41.

[25] Seno, H.; Nakase, H. \& Chiba, T. (2005). Usefulness of famotidine in functional dyspepsia patient treatment: comparison among prokinetic, acid suppression and anxiety therapies. Aliment. Pharmacol. Ther. 21 (Suppl. 2): 32-36.

[26] Talley, N.J.; Vakil, N.B. \& Moayyedi, P. (2005). American gastroenterological association technical review on the evaluation of dyspepsia. Gastroenterol. 129: 1756-1780.

[27] Matsunaga, Y.; Yamamoto, O. \& Ueki, S. (1994). Inhibition of phase III activity by acid in canine stomach. Regul. Pept. 52: 61-72.

[28] Simrén, M.; Vos, R. \& Janssens, J. (2003). Acid infusion enhances duodenal mechanosensitivity in healthy subjects. Am. J. Physiol. 285: G309-G315.

[29] Hunt, J.N. \& Knox, M.T. (1972). The slowing of gastric emptying by four strong acids and three weak acids. J. Physiol. (Lond.) 222: 187-208.

[30] Woodtli, W. \& Owyang, C. (1995). Duodenal pH governs interdigestive motility in humans. Am. J. Physiol. 268: G146-G152.

[31] Lu, Y.X. \& Owyang, C. (1999). Duodenal acid-induced gastric relaxation is mediated by multiple pathways. Am. J. Physiol. 276: G1501-G1506.

[32] Danzer, M.; Jocic, M. \& Samberger, C. (2004). Stomach-brain communication by vagal afferents in response to luminal acid backdiffusion, gastrin, and gastric acid secretion. Am. J. Physiol. 286: G403-G411.

[33] Raybould, H.E. \& Hölzer, H.H. (1993). Duodenal acid-induced inhibition of gastric motility and emptying in rats. Am. J. Physiol. 265: G540-G546. Cooke, 1974;

[34] Mearadji, B.; Straathof, J.W. \& Lamers, C.B. (1999). Effect of gastrin on proximal gastric motor function in humans. Neurogastroenterol. Motil. 11: 449-455.

[35] Parkman, H.P.; Urbain, J.L. \& Knight, L.C. (1998). Effect of gastric acid suppressants on human gastric motility. Gut 42: 243-250.

[36] Lamb, K.; Kang, Y.M. \& Gebhart, G.F. (2003). Gastric inflammation triggers hypersensitivity to acid in awake rats. Gastroenterol. 125: 1410-1418. 
[37] Scicho, R.; Liebmann, I. \& Lippe, I.T. (2005). Extracellular signal-regulated kinase-1 and -2 are activated by gastric luminal injury in dorsal root ganglion neurons via N-methyl- D-aspartate receptors. Neuroscience 134: 505-514.

[38] Sakurai, J.; Obata, K. \& Ozaki, N. (2008). Activation of extracellular signal-regulated protein kinase in sensory neurons after noxious gastric distention and its involvement in acute visceral pain in rats. Gastroenterol. 134: 1094-1103.

[39] Ugawa, S.; Ueda, T. \& Ishida, Y. (2002). Amiloride-blockable acid-sensing ion channels are leading acid sensors expressed in human nociceptors. J. Clin. Invest. 110: 11851190.

[40] Akiba, Y.; Nakamura, M. \& Nagata, H. (2002). Acid-sensing pathway in rat gastrointestinal mucosa. J. Gastroenterol. 37: 133-138.

[41] Yagi, J.; Adachi, K. \& Arima, N. (2005). A prospective randomized comparative study on the safety and tolerability of transnasal esophagogastroduodenoscopy. Endoscopy 37: 1226-1231.

[42] Ishii, M.; Manabe, N. \& Kusunoki, H. (2008). Real-time evaluation of dyspeptic symptoms and gastric motility induced by duodenal acidification using noninvasive transnasal endoscopy. J. Gastroenterol. 43: 935-941.

[43] Ishii, M.; Kusunoki, H. \& Manabe, N. (2010). Evaluation of duodenal hypersensitivity induced by duodenal acidification using transnasal endoscopy. J. Gastroenterol. Hepatol. 25: 913-918. 


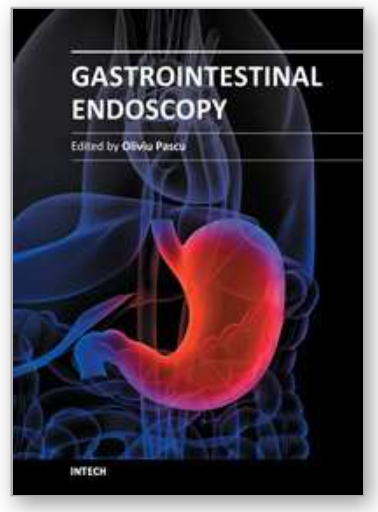

\author{
Gastrointestinal Endoscopy \\ Edited by Prof. Oliviu Pascu
}

ISBN 978-953-307-385-9

Hard cover, 272 pages

Publisher InTech

Published online 19, July, 2011

Published in print edition July, 2011

Endoscopy has had a major impact in the development of modern gastroenterology. By using different data it provided a better understanding of pathogenic mechanisms, described new entities and changed diagnostic and therapeutic strategies. Meanwhile, taking advantage of many technical advances, endoscopy has had a developed spectacularly. Video-endoscopes, magnification, confocal and narrow-band imaging endoscopes, endoscopic ultrasounds and enteroscopes emerged. Moreover, endoscopy has surpassed its function as an examination tool and it became a rapid and efficient therapeutic tool of low invasiveness. InTech Open Access Publisher selected several known names from all continents and countries with different levels of development. Multiple specific points of view, with respect to different origins of the authors were presented together with various topics regarding diagnostic or therapeutic endoscopy. This book represents a valuable tool for formation and continuous medical education in endoscopy considering the performances or technical possibilities in different parts of the world.

\title{
How to reference
}

In order to correctly reference this scholarly work, feel free to copy and paste the following:

Manabu Ishii, Hiroaki Kusunoki, Noriaki Manabe, Tomoari Kamada, Ken-ichi Tarumi, Hiroshi Matsumoto, Motonori Sato, Yoshiyuki Yamanaka, Takahisa Murao, Hideaki Tsutsui, Akiko Shiotani, Jiro Hata and Ken Haruma (2011). Evaluation of Duodenal Hypersensitivity to Acid Using Transnasal Endoscopy, Gastrointestinal Endoscopy, Prof. Oliviu Pascu (Ed.), ISBN: 978-953-307-385-9, InTech, Available from:

http://www.intechopen.com/books/gastrointestinal-endoscopy/evaluation-of-duodenal-hypersensitivity-to-acidusing-transnasal-endoscopy

\section{INTECH}

open science | open minds

\section{InTech Europe}

University Campus STeP Ri

Slavka Krautzeka 83/A

51000 Rijeka, Croatia

Phone: +385 (51) 770447

Fax: +385 (51) 686166

www.intechopen.com

\section{InTech China}

Unit 405, Office Block, Hotel Equatorial Shanghai

No.65, Yan An Road (West), Shanghai, 200040, China

中国上海市延安西路65号上海国际贵都大饭店办公楼 405 单元

Phone: +86-21-62489820

Fax: +86-21-62489821 
(C) 2011 The Author(s). Licensee IntechOpen. This is an open access article distributed under the terms of the Creative Commons Attribution 3.0 License, which permits unrestricted use, distribution, and reproduction in any medium, provided the original work is properly cited. 